\title{
Eficacia del cepillado con cloruro de sodio versus pasta dental en la disminución del Streptococcus mutans.
}

\section{Effectiveness of brushing with sodium chloride versus toothpaste in Streptococcus mutans decreased.}

\author{
César Cayo ${ }^{1}$, Raúl Pacora ${ }^{2}$, Cristian Escurra ${ }^{3}$, Javier Ramos ${ }^{4}$, Rosa Arévalo ${ }^{5}$, Daniela Depaz ${ }^{6}$, Anita \\ Galindo $^{7}$, Tania León ${ }^{8}$, Gleiky Robles 9
}

http://dx.doi.org/10.21503/CienciayDesarrollo.2013.v16i1.05

\section{RESUMEN}

Objetivo. Determinar el mejor agente anticaries midiendo la eficacia de la aplicación del cepillado con cloruro de sodio diluido en agua al $5 \%$, pasta dental convencional y agua sola en la disminución del Streptococcus mutans presente en la placa dental. Materiales y Métodos. El presente trabajo es experimental de tipo comparativo, tomando como muestra a los 30 alumnos del 2 do ciclo $(2012$ - 1) de la Escuela Académico Profesional de Estomatología de la Universidad Alas Peruanas (filial - Huacho), luego se procedió a formar 3 grupos de 10 cada uno (aplicación del cepillado con cloruro de sodio al 5\%, pasta dental y agua sola) y se hizo de forma aleatoria utilizando el cuadro de números de 5 dígitos para muestreo no probabilístico. Para el recuento de colonias se hizo la observación directa de Streptococcus mutans (tomados de la placa dental de los muestreados y sembrados en agar mitis salivarius con telurito de potasio) esto se realizó en 3 semanas, tomando una muestra inicial y luego cada 7 días para determinar el número de colonias. Los datos son procesados estadísticamente y presentados en cuadros con sus respectivos gráficos. Para el análisis comparativo de colonias se utilizó la prueba Duncan. Resultados. Tomando como referencia la primera y última muestra se observó que el número de colonias disminuyeron en un 95,9\% en el caso de la aplicación con cloruro de sodio al 5\%; 79,1\% en el caso del uso con pasta dental y $74 \%$ en el caso del cepillado solo con agua. Conclusión. Los tres métodos de cepillado reducen considerablemente el número de colonias, sin embargo es el grupo que se cepilló con cloruro de sodio diluido al 5\% quien reduce más el número de colonias al finalizar el tratamiento a la tercera semana de evaluación.

Palabras Clave: Pasta dental, cloruro de sodio al 5\%, Streptococcus mutans

\section{ABSTRACT}

Objective. Determining the best anticaries agent by measuring the effectiveness of the application of brushing with dilute sodium chloride in water at $5 \%$, conventional toothpaste and water alone in reducing the Streptococcus mutans present in dental plaque. Materials and Methods. This work is experi-

\footnotetext{
1 Docente de patología, histología, embriología y genética de la EAP de Estomatología y Obstetricia de la UAP sede Huacho. cesarcayorojas@gmail.com 2 Docente de fisiología de la E.A.P. de Estomatología de la UAP sede Huacho. rapdent@gmail.com

3 Docente de estadística de UAP sede Huacho. crivan16@hotmail.com

4 Docente de anatomía y prótesis fija de UAP sede Huacho. Jd_dent@hotmail.com

5 Alumna del 8vo ciclo de la E.A.P. Estomatología de la UAP sede Huacho. chicax1@hotmail.com

6 Alumna del 8vo ciclo de la E.A.P. de Estomatología de la UAP sede Huacho. daniela2392@hotmail.com

7 Alumna del 9no ciclo de la E.A.P. Estomatología UAP sede Huacho. ani.g.r@hotmail.com

8 Alumna del 7mo ciclo de la E.A.P. Estomatología UAP sede Huacho. tanialeon_2010@hotmail.com

9 Alumna del 9no ciclo de la E.A.P. Obstetricia UAP sede Huacho. glei_blexez@hotmail.com
} 
mental, comparative, taking as sample the 30 students of the 2 nd cycle (2012-1) Academic Professional School of Dentistry, Alas Peruanas University (subsidiary - Huacho), then proceeded to form 3 groups of 10 each (application toothbrushing with sodium chloride $5 \%$, toothpaste and water alone) and made at random using Table 5 digit number for non-probability sampling. For colony counting was direct observation of Streptococcus mutans (dental plaque taken from the sampled and mitis salivarius agar seeded with potassium tellurite) this was done in three weeks, taking an initial sample and then every 7 days to determining the number of colonies. The data will be statistically processed and presented in tables with their graphics. For comparative analysis of colonies Duncan test was used. Results. Taking as reference the first and last sample was observed that the number of colonies decreased by $95.9 \%$ in the case of the application with sodium chloride $5 \% 79.1 \%$ for use with toothpaste and $74 \%$ for single brushing with water. Conclusion. The three methods of brushing significantly reduced the number of colonies, however, is the group that brush with dilute sodium chloride $5 \%$ who further reduced the number of colonies at the end of the third week treatment evaluation.

Keywords: Toothpaste, sodium chloride 5\%, Streptococcus mutans.

\section{INTRODUCCIÓN}

En reiteradas ocasiones la Organización Mundial de la Salud (OMS) y la Organización Panamericana de la Salud (OPS) han expresado que la caries dental es una enfermedad infecciosa que afecta la salud en general y la calidad de vida de las personas. Prueba de ello es que la caries dental está catalogada en América Latina como un problema de salud pública.

Por ello se han realizado diferentes investigaciones durante los últimos años con la finalidad de disminuir la caries, entre las relacionadas con nuestra investigación tenemos:

En el año 1998, Gispert A., Cantillo E., Rivero L., Oramas R. hicieron su estudio comparativo del efecto del cepillado con una crema dental con propóleos rojos y de un gel con clorofila, cuyo objetivo fue comparar el efecto del gel dental de clorofila y de la crema dental con propóleos rojos sobre varios parámetros relacionados con la caries dental. Analizaron comparativamente el efecto de un gel dental de clorofila y de una crema dental con propóleos rojos sobre varios parámetros relacionados con la caries dental, en escolares que se cepillaron durante 21 días con dichos productos. Se obtuvieron resultados favorables principalmente en la disminución del grado de infección por Streptococcus mutans y la elevación de la capacidad individual de remineralización; salvo en este último no hubo diferencias estadísticamente significativas. (9)

En el año 2005, Díaz S. Ana et al. estudiaron los efectos de los colutorios orales con fluoruro de sodio al $0,05 \%$ y agua con sal al $5 \%$ sobre la placa bacteriana y el pH salival. Odontología. El propósito de esta investigación consistió en evaluar los efectos de dos colutorios orales (un colutorio con fluoruro de sodio al 0,05\% y un colutorio de agua con sal al 5\%) sobre la placa bacteriana y el pH salival en una población de soldados del ejército.

Los resultados del trabajo de investigación indicaron que tanto el colutorio con fluoruro de sodio al $0,05 \%$ como el colutorio con agua con sal al $5 \%$ se comportan de maneras similar sobre la placa bacteriana, disminuyéndola al cabo de 40 días; mientras que ninguno de los colutorios fue capaz de alterar el $\mathrm{pH}$ salival en formas significativas. (1)

Durante los meses de Julio a Diciembre del 2010, Rupesh S., Winnier J., Nayak U., Rao A., Reddy N. realizaron un estudio de evaluación comparativa de los efectos de un enjuague bucal que contiene alumbre y un enjuague con solución salina 
saturada en los niveles salivales de Streptococcus mutans. Teniendo en cuenta el potencial efecto antimicrobiano de la solución salina saturada y la solución de alumbre, el estudio ha tratado de comparar y evaluar los efectos del enjuague de solución salina saturada y un enjuague bucal de alumbre al 0,02 M en los niveles salivales de $S$. mutans en niños.

Los niños que utilizan el enjuague con solución salina saturada y el enjuague de alumbre mostraron reducciones estadísticamente significativas en el recuento de $S$. mutans salivales después de 10 días, y también después de 21 días. Después de 21 días, los grupos de enjuague con solución salina saturada y el enjuague de alumbre mostraron diferencias estadísticamente significativas sobre el grupo del enjuague placebo.

Una vez más, el grupo con enjuague de alumbre mostró una diferencia estadísticamente significativa sobre el grupo de enjuague con solución salina saturada. (7)

Por lo tanto, la presente investigación es considerada de suma importancia debido a que propone una alternativa económica, además que concientiza a la población de mantener una buena higiene oral adecuada con el uso de la sal y el agua.

Es por estas razones que nos planteamos el siguiente problema: ¿Cuál es la eficacia de la aplicación del cepillado con cloruro de sodio diluido en agua al $5 \%$, pasta dental y agua sola en la disminución del Streptococcus mutans presente en la placa dental?

La hipótesis principal planteada es: El cepillado con cloruro de sodio diluido en agua al 5\% es el mejor agente anticaries que la pasta dental y el agua sola porque disminuye más eficazmente la cantidad de Streptococcus mutans en la placa dental. Las hipótesis derivadas son 5: a) El cepillado con cloruro de sodio diluido en agua al 5\% es eficaz en la reducción de la cantidad de Streptococcus mutans en placa dental. b) El cepillado con pasta dental convencional es eficaz en la reducción de la cantidad de Streptococcus mutans en placa dental. c) El cepillado con agua sola es eficaz en la reducción de la cantidad de Streptococcus mutans en placa dental. d) Existen diferencias significativas de eficacia del cepillado con cloruro de sodio diluido en agua al $5 \%$ en comparación con la pasta dental convencional. e) Existen diferencias significativas de eficacia del cepillado con agua sola en comparación con la pasta dental convencional.

Como objetivo principal se planteó el siguiente: Determinar el mejor agente anticaries midiendo la eficacia de la aplicación del cepillado con cloruro de sodio diluido en agua al $5 \%$, pasta dental convencional y agua sola en la disminución del Streptococcus mutans presente en la placa dental, a través de 5 objetivos específicos: a) Determinar la eficacia del cepillado con cloruro de sodio al 5\% en la reducción de Streptococcus mutans en la placa dental. b) Determinar la eficacia del cepillado con pasta dental convencional en la reducción de Streptococcus mutans en la placa dental. c) Determinar la eficacia del cepillado solo con agua en la reducción de Streptococcus mutans en la placa dental. d) Establecer las diferencias significativas de eficacia del cepillado con cloruro de sodio diluido en agua al 5\% en comparación con la pasta dental convencional. e) Establecer las diferencias significativas de eficacia del cepillado con agua sola en comparación con la pasta dental convencional.

Dentro de las limitaciones se determinó que el trabajo de investigación se realizó con los alumnos del segundo ciclo $(2012-1)$ de estomatología, entre el 18 de junio al 9 de julio del 2012 en la Universidad Alas Peruanas - filial Huacho.

\section{MATERIALES Y MÉTODOS}

El presente trabajo es experimental de tipo comparativo, tomando a como muestra a los 30 alumnos del 2 do ciclo $(2012$ - 1) de la Escue- 
la Académico Profesional de Estomatología de la Universidad Alas Peruanas (filial - Huacho), luego se procedió a formar 3 grupos de 10 cada uno (aplicación del cepillado con cloruro de sodio al 5\%, pasta dental y agua sola) y se hizo de forma aleatoria utilizando el cuadro de números de 5 dígitos para muestreo no probabilístico.

Para el recuento de colonias se hizo la observa-

\section{RESULTADOS}

ción directa de Streptococcus mutans (tomados de la placa dental de los muestreados y sembrados en agar mitis salivarius con telurito de potasio) esto se realizó en 3 semanas, tomando una muestra inicial y luego cada 7 días para determinar el número de colonias.

Los datos serán procesados estadísticamente y presentado en cuadros con sus respectivos gráficos. Para el análisis comparativo de colonias se utilizó la prueba Duncan.

Tabla 1: Grupos de pacientes de acuerdo al tratamiento

Grupo 1. Cloruro de sodio diluido en agua al 5\%

\begin{tabular}{|c|c|c|c|c|c|}
\hline \multirow{2}{*}{ Grupo } & \multicolumn{5}{|c|}{ RECUENTO DE COLONIAS } \\
\hline & CÓDIGO & $18 / 06 / 2010$ & $25 / 06 / 2010$ & $02 / 07 / 2010$ & $09 / 07 / 2010$ \\
\hline \multirow{10}{*}{ A } & 1S & 32 & 16 & 6 & 10 \\
\hline & $2 S$ & 211 & 123 & 53 & 3 \\
\hline & $3 S$ & 110 & 90 & 32 & 5 \\
\hline & $4 S$ & 191 & 102 & 40 & 3 \\
\hline & $5 S$ & 235 & 54 & 8 & 5 \\
\hline & $6 S$ & 195 & 52 & 6 & 11 \\
\hline & $7 S$ & 161 & 87 & 73 & 6 \\
\hline & $8 S$ & 299 & 62 & 32 & 7 \\
\hline & $9 S$ & 147 & 52 & 27 & 8 \\
\hline & $10 S$ & 131 & 53 & 14 & 9 \\
\hline
\end{tabular}

Grupo 2. Pasta dental (control)

\begin{tabular}{|c|c|c|c|c|c|}
\hline & $1 \mathrm{P}$ & 115 & 80 & 11 & 7 \\
\hline & $2 \mathrm{P}$ & 0 & 100 & 45 & 15 \\
\hline \multirow{3}{*}{$\mathrm{3P}$} & 4 & 97 & 18 & 12 \\
\hline & $4 \mathrm{P}$ & 42 & 40 & 15 & 25 \\
\hline & $5 \mathrm{P}$ & 25 & 16 & 13 & 7 \\
\hline & $6 \mathrm{P}$ & 41 & 37 & 30 & 13 \\
\hline & $7 \mathrm{P}$ & 107 & 25 & 12 & 12 \\
\hline & $8 \mathrm{P}$ & 110 & 123 & 36 & 17 \\
\hline & $10 \mathrm{P}$ & 189 & 59 & 18 & 15 \\
\hline
\end{tabular}

Grupo 3. Cepillo con agua

\begin{tabular}{|c|c|c|c|c|c|}
\hline & $1 C$ & 110 & 67 & 58 & 27 \\
\hline & $2 C$ & 118 & 73 & 12 & 36 \\
\hline $3 C$ & 6 & 80 & 18 & 25 \\
\hline & $4 C$ & 71 & 30 & 8 & 24 \\
\hline & $5 C$ & 188 & 21 & 18 & 50 \\
\hline & $6 C$ & 144 & 25 & 2 & 24 \\
\hline & $7 C$ & 221 & 87 & 13 & 20 \\
\hline & $9 C$ & 63 & 105 & 31 & 9 \\
\hline & $9 C$ & 15 & 66 & 6 & 24 \\
\hline
\end{tabular}


Tabla 2: Comparaciones múltiples entre grupos

Variable dependiente: Número de colonias

\begin{tabular}{|l|l|l|c|c|c|c|c|}
\hline & $\begin{array}{l}\text { (I) } \\
\text { GRUPO }\end{array}$ & $\begin{array}{l}(\mathrm{J}) \\
\text { GRUPO }\end{array}$ & $\begin{array}{c}\text { Diferencia entre } \\
\text { medias }(\mathrm{I}-\mathrm{J})\end{array}$ & $\begin{array}{c}\text { Error } \\
\text { tipificado }\end{array}$ & Significación & \multicolumn{2}{|c|}{$\begin{array}{c}\text { Intervalo de confianza } \\
\text { al 95\%. }\end{array}$} \\
\hline & & Límite inferior & $\begin{array}{c}\text { Límite } \\
\text { superior }\end{array}$ & Límite inferior & $\begin{array}{c}\text { Límite } \\
\text { superior }\end{array}$ & $\begin{array}{c}\text { Límite } \\
\text { inferior }\end{array}$ \\
\hline DMS & sal & Pasta & $27,70\left(^{*}\right)$ & 8,703 & 0,002 & 10,45 & 44,95 \\
\hline & & Agua & 16,60 & 8,703 & 0,059 & $-0,65$ & 33,85 \\
\hline & Pasta & Sal & $-27,70\left(^{*}\right)$ & 8,703 & 0,002 & $-44,95$ & $-10,45$ \\
\hline & & agua & $-11,10$ & 8,703 & 0,205 & $-28,35$ & 6,15 \\
\hline & agua & Sal & $-16,60$ & 8,703 & 0,059 & $-33,85$ & 0,65 \\
\hline & & pasta & 11,10 & 8,703 & 0,205 & $-6,15$ & 28,35 \\
\hline
\end{tabular}

Basado en las medias observadas.

* La diferencia de medias es significativa al nivel 0,05.

A diferencia de los grupos, en los días se puede apreciar que el número de colonias resultantes difieren en los cuatro días en que se tomaron los datos. Y las diferencias más marcadas están en el cuarto día, por lo que podemos afirmar con una confianza del $95 \%$ que los tres métodos de cepillado reducen considerablemente el número de colonias, sin embargo es el grupo que se cepilló con cloruro de sodio diluido al $5 \%$ quien reduce más el número de colonias al cuarto día, tal como se puede observar con mayor claridad en las figuras $\mathrm{Ns}^{\circ} 1,2$ y 3.

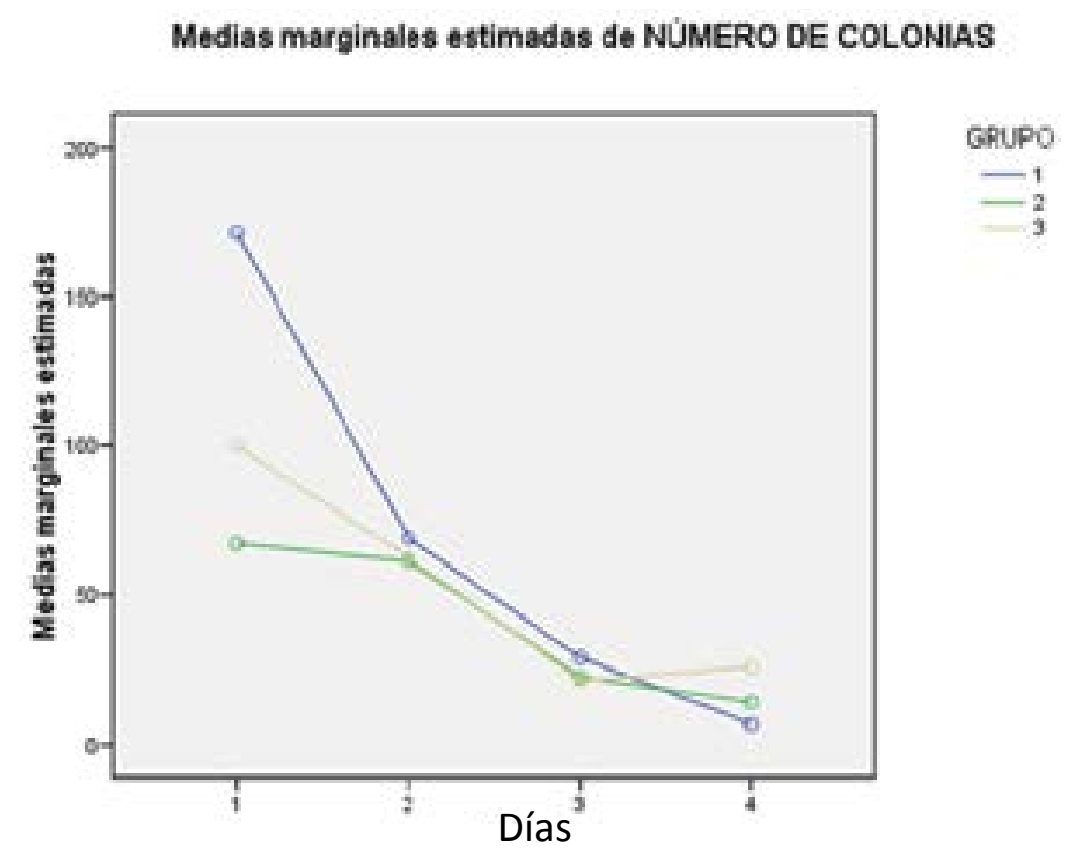

Figura 1. Número de colonias promedio para los tres grupos evaluados en los cuatro días 


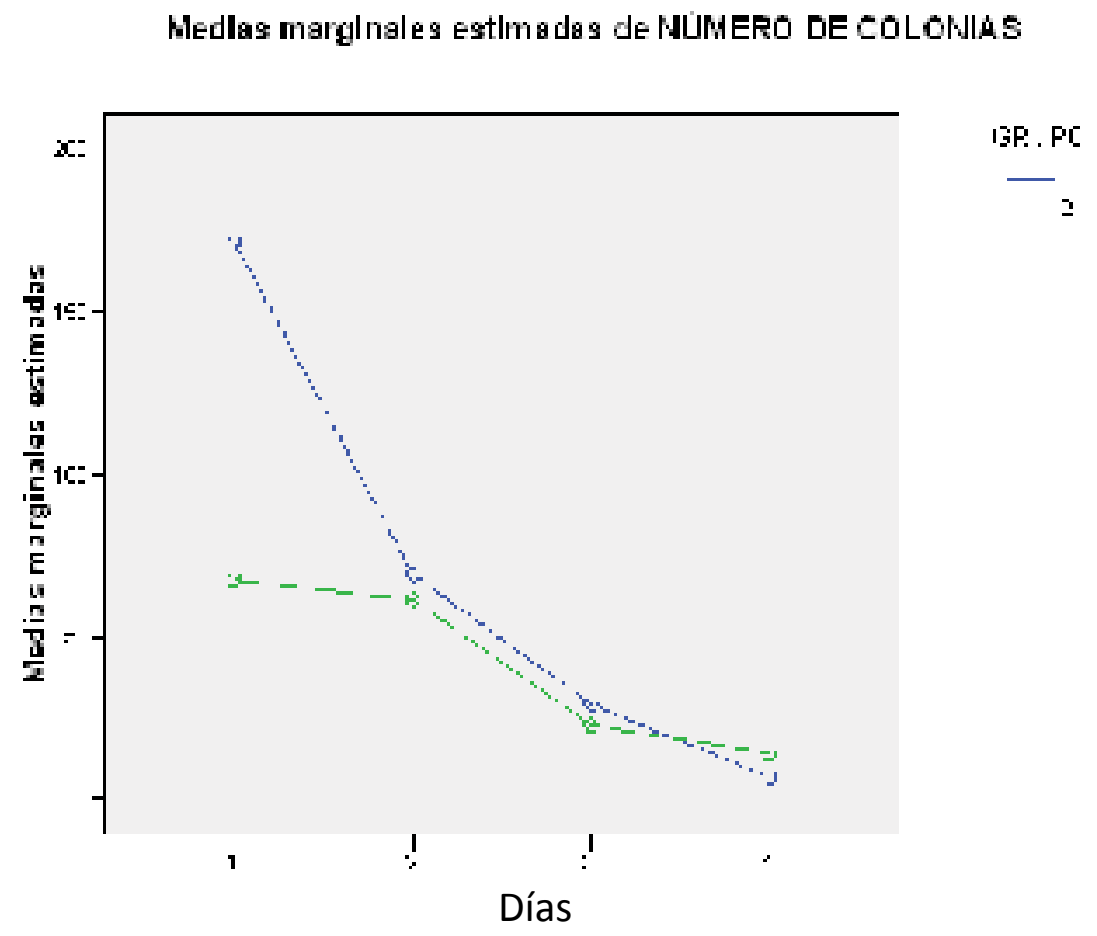

Figura 2. Número de colonias promedio entre el grupo de cepillado con cloruro de sodio y pasta dental en los cuatro días evaluados

Medlas marginales estimadas de NÜHeRo de CoLonias

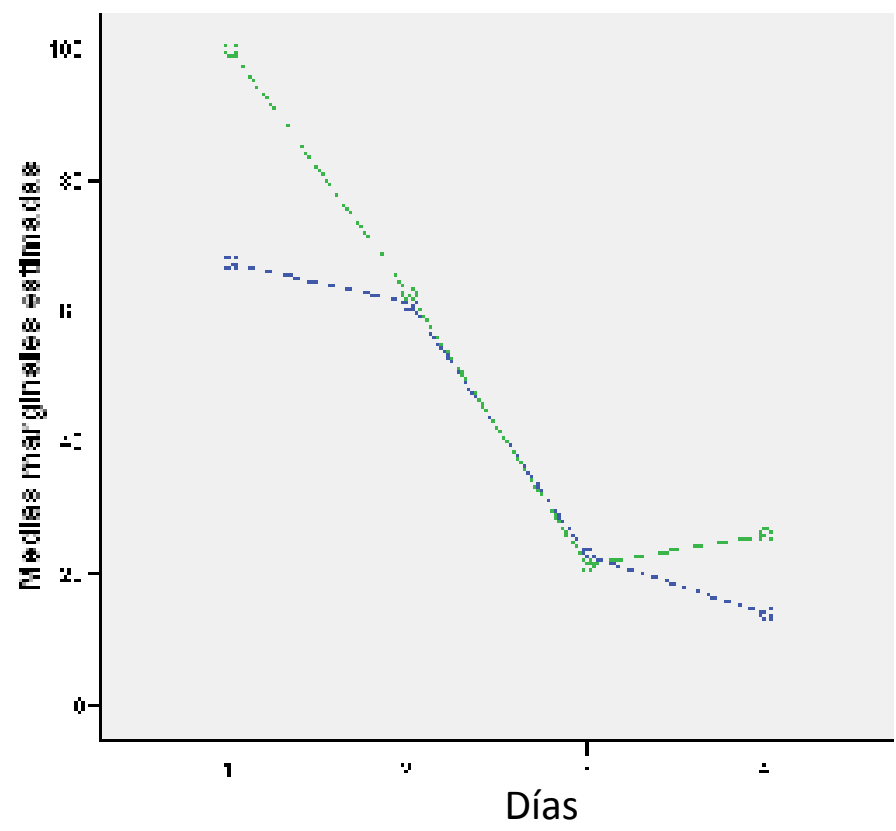

$32 \mathrm{JPO}$

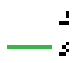

Figura 3. Número de colonias promedio entre el grupo de cepillado con pasta dental y agua en los cuatro días evaluados 
Tabla 3: Promedio de colonias por día y grupo

En la siguiente tabla se aprecia el promedio de colonias por día y por grupo. Donde se nota claramente que el cloruro de sodio diluido al $5 \%$ es más eficiente que el resto de los grupos dado que al cuarto día en el grupo de cepillado con cloruro de sodio (grupo 1), el número de colonias se reduce considerablemente mucho más que el grupo de cepillado con pasta dental (grupo 2). Sin embargo, el grupo que se cepilló solo con agua su reducción se dio entre el tercer y cuarto día. Tal como se puede observar en las figuras 4,5 y 6 .

Tabla 3. Promedio de colonias por día para cada uno de los grupos

\begin{tabular}{cccc} 
GRUPO & DÍA & $\begin{array}{c}\text { NÚMERO DE } \\
\text { COLONIAS PROMEDIO } \\
\text { POR DÍA }\end{array}$ & $\begin{array}{c}\text { NÚMERO DE } \\
\text { COLONIAS PROMEDIO } \\
\text { POR GRUPO }\end{array}$ \\
\hline Cloruro & 1 & 171 & \\
de sodio & 2 & 69 & 69 \\
Grupo 1 & 3 & 29 & \\
& 4 & 7 & 41 \\
Pasta dental & 2 & 67 & \\
Grupo 2 & 3 & 23 & \\
& 4 & 14 & \\
\hline Agua & 1 & 100 & \\
Grupo 3 & 2 & 63 & \\
\hline
\end{tabular}

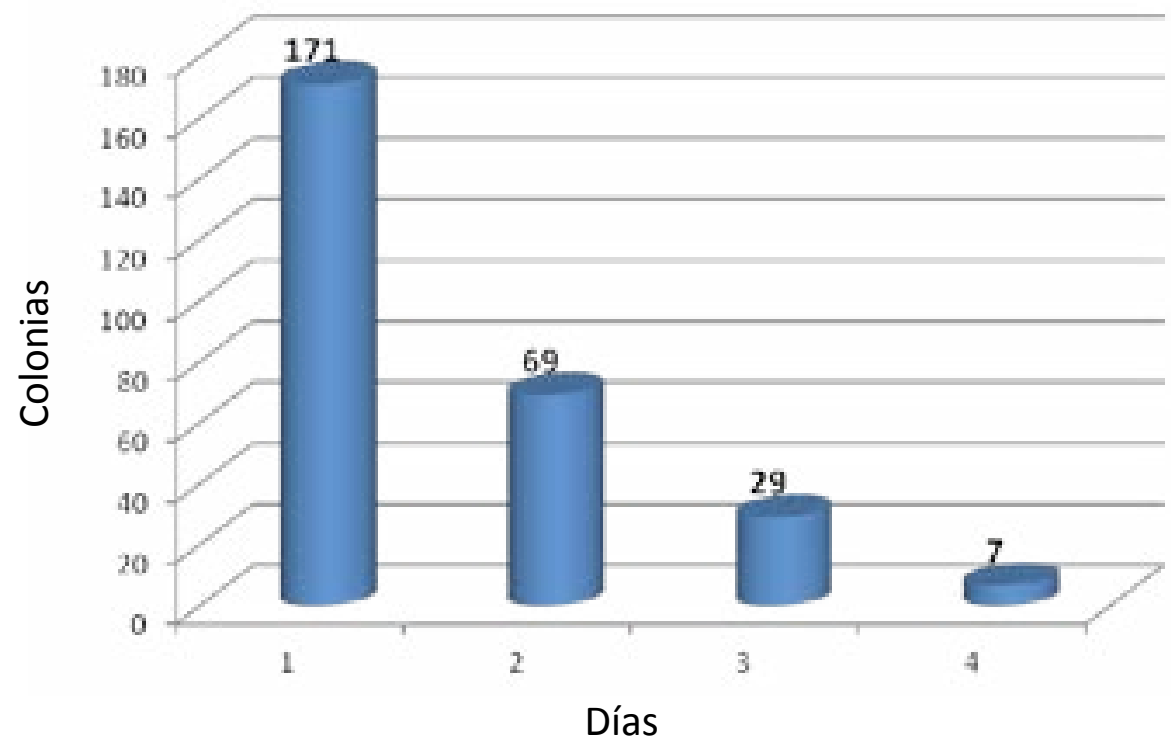

Figura 4. Número de colonias promedio por día en el grupo que se cepilló con cloruro de sodio diluido al 5\% 


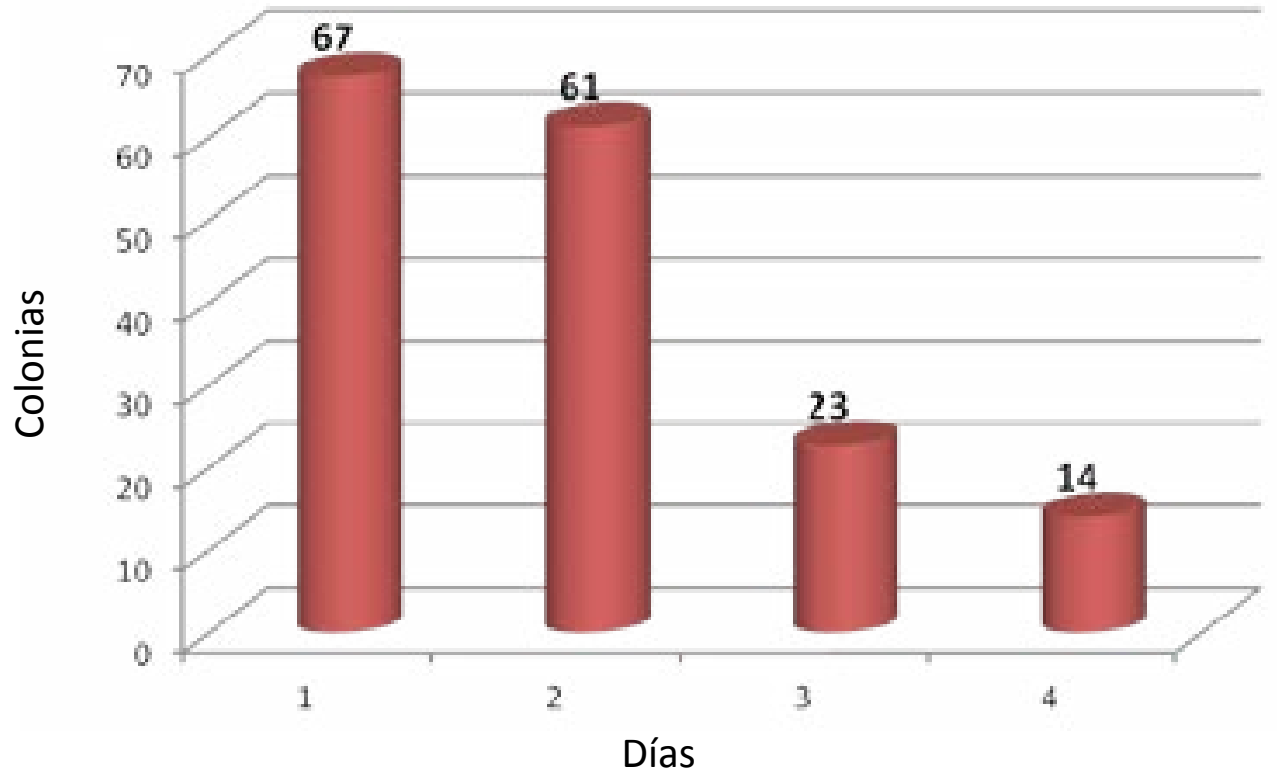

Figura 5. Número de colonias promedio por día en el grupo que se cepilló con pasta dental.

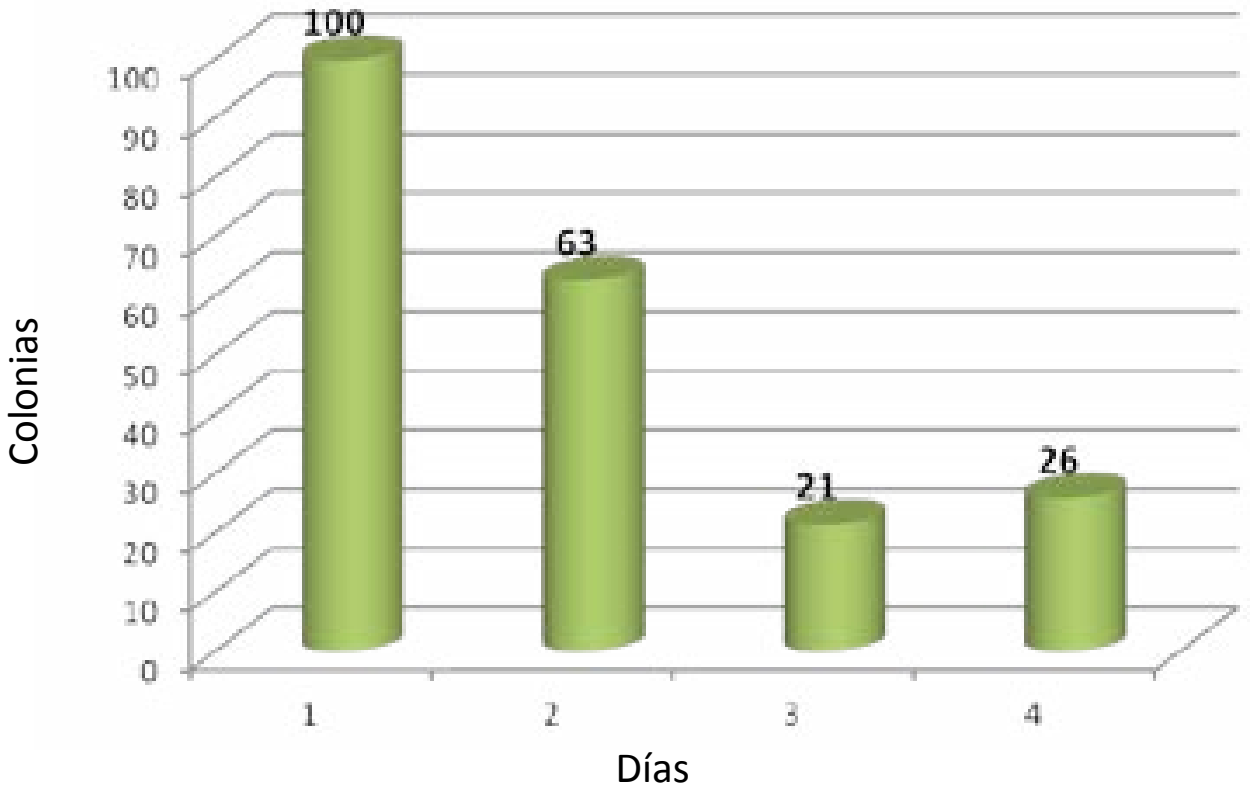

Figura 6. Número de colonias promedio por día en el grupo que se cepilló sólo con agua. 


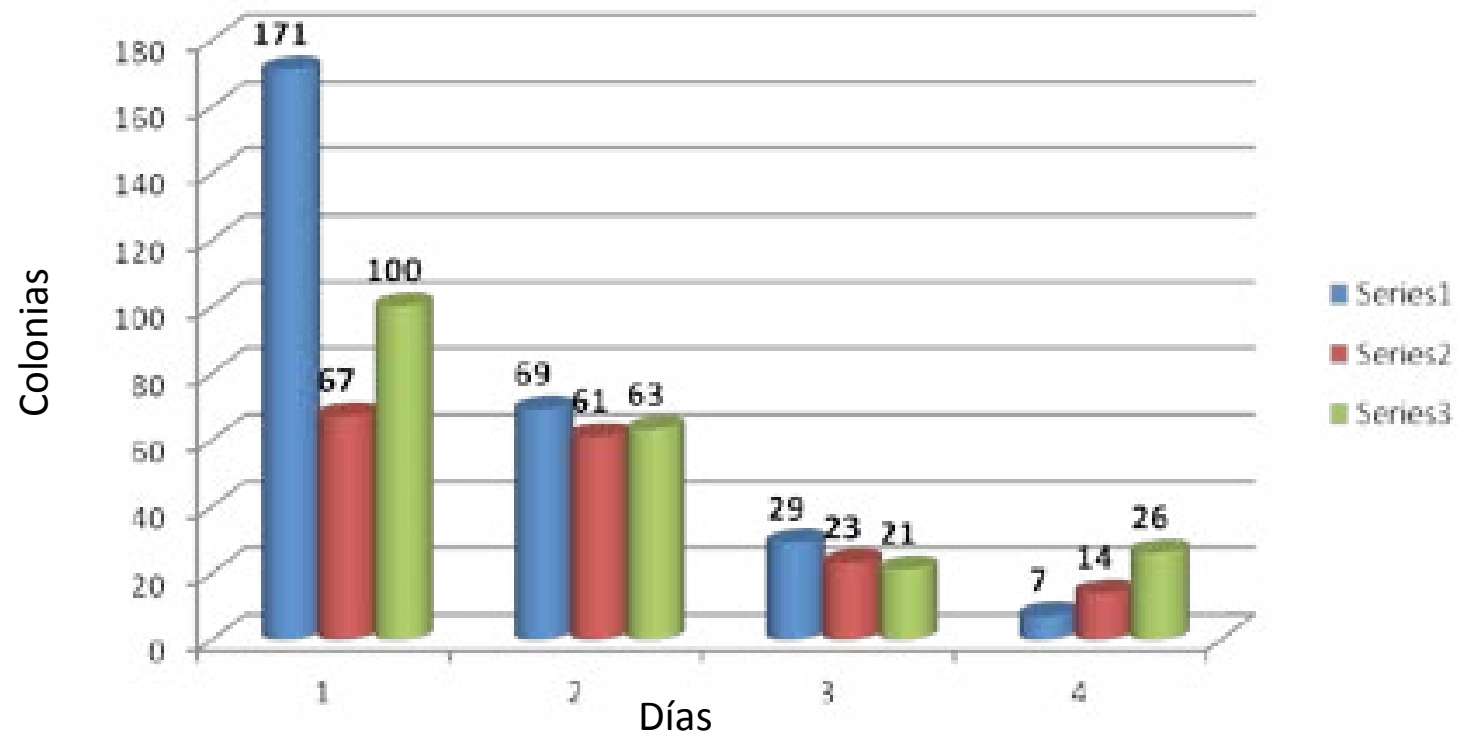

Nota: Serie 1, grupo cloruro de sodio.

Serie 2, grupo de pasta dental.

Serie 3, grupo de solo agua.

Figura 7. Número de colonias promedio por día para los tres grupos de cepillado

\section{CONCLUSIONES}

Se puede afirmar con una confianza del $95 \%$ que los tres métodos de cepillado reducen considerablemente el número de colonias; sin embargo es el grupo que se cepilló con cloruro de sodio diluido al $5 \%$ quien reduce más el número de colonias al finalizar el tratamiento a la tercera semana de evaluación.

Al realizar las comparaciones múltiples entre grupos podemos afirmar a un nivel de confianza del 95\%, que:

- Existe eficacia significativa en la reducción de la placa bacteriana en el grupo que se cepilló con cloruro de sodio al $5 \%$, siendo notoria a partir de la segunda aplicación.

- Existe eficacia significativa en la reducción de la placa bacteriana en el grupo que se cepilló con pasta dental, disminuyendo paulatinamente siendo mucho más notoria a partir de la tercera aplicación.

- Existe eficacia significativa en la reducción de la placa bacteriana en el grupo que se cepilló solo con agua, donde es evidente como en las muestras anteriores la disminución de la placa bacteriana.

- Al realizar la comparación en los resultados se evidencia que el cepillado con cloruro de sodio al diluido en agua al $5 \%$ es más eficaz en la disminución de colonias respecto al cepillado con pasta dental, mostrando en los resultados diferencias significativas.

- Al comparar los resultados de eficacia en la disminución de colonias entre el cepillado con pasta dental y el cepillado con agua sola, es evidente que existen diferencias significativas de reducción de colonias por parte de la primera aplicación mencionada respecto al segundo agente de aplicación.

\section{DISCUSIÓN}

De acuerdo con las investigaciones citadas anteriormente, se muestran diversos estudios similares para controlar la placa bacteriana en el individuo. 
Teniendo resultados análogos a nuestro estudio, como el de Díaz S. Ana, et. al. (2005) que evaluó los efectos de dos colutorios orales (un colutorio con fluoruro de sodio al $0,05 \%$ y un colutorio de agua con sal al 5\%) sobre la placa bactriana y el $\mathrm{pH}$ salival, actuando de forma positiva, indicando que tanto el colutorio con fluoruro de sodio al $0,05 \%$ como el colutorio con agua con sal al 5\% se comportan de maneras similar sobre la placa bacteriana, disminuyéndola al cabo de 40 días; mientras que ninguno de los colutorios fue capaz de alterar el $\mathrm{pH}$ salival de formas significativas (1), esto respalda nuestro trabajo porque también se obtuvo resultados positivos con el tratamiento de cloruro de sodio diluido al 5\% que se hizo notoria a partir de la segunda aplicación.

Además tenemos a Rupesh S., Winnier J., Nayak U., Rao A., Reddy N. (2010) donde trató de comparar y evaluar los efectos del enjuague de solución salina saturada y un enjuague bucal de alumbre al 0,02 $\mathrm{M}$ en los niveles salivales de $S$. mutans en niños; obteniendo resultados positivos a los 10 días y a los 21 días después de aplicado el tratamiento. Después de 21 días, los grupos de enjuague con solución salina saturada y el enjuague de alumbre mostraron diferencias estadísticamente significativas sobre el grupo del enjuague placebo. Una vez más, el grupo con enjuague de alumbre mostró una diferencia estadísticamente significativa sobre el grupo de enjuague con solución salina saturada (7). En esta investigación también se obtuvo resultados similares al aplicar el tratamiento con cloruro de sodio diluido al $5 \%$ que se hizo notoria a partir de la segunda aplicación.

Teniendo evidencia científica vigente sobre los efectos del cloruro de sodio diluido al 5\% en comparación con la pasta dental y con otros productos aplicados para cada investigación, demuestra la gran eficacia de este producto si se aplica de forma adecuada y periódica como tratamiento alternativo en la disminución de la placa bacteriana.

\section{BIBLIOGRAFÍA}

1. Cárdenas JD. 2003. Odontología Pediátrica. Colombia 3era Ed. Editorial Corporación para investigaciones biológicas.

2. Díaz Soriano A., et.al. 2005. Efectos de los colutorios orales con fluoruro de sodio al $0.05 \%$ y agua con sal al 5\% sobre la placa bacteriana y el $p H$ salival. Odontología San Marquina. 8(1):6-9.

3. Gispert Abreu E., Cantillo Estrada Elena, Rivero López Aracelys, Oramas Rodríguez Berta. 1998. Estudio comparativo del efecto del cepillado con una crema dental con propóleos rojos y de un gel con clorofila. Rev. Cubana Estomatol.

4. Gutiérrez Prieto, S J. 2006. Fundamento de ciencias básicas aplicadas a la odontología. 1era Ed. Bogotá. Editorial: Pontificia Universidad Javeriana. Facultad de Odontología.

5. Madigan M., Martinko J., Parker J. Brock 2004. Biología de los microorganismos. $10^{a}$ Edición.

6. Gartner P, Leslie. L. Hiatt, J. 2007. Texto atlas de Histología. Tercera Edición Mc Grawhill Editorial.

7. Revista de la Asociación Dental Mexicana. Placa dentobacteriana. Volume 60 Number 1 JanuaryFebruary 2003.

8. Rupesh S, Winnier JJ, Nayak UA, Rao AP, Reddy NV. 2010. Evaluación comparativa de los efectos de un enjuague bucal que contiene alumbre y un enjuague con solución salina saturada en los niveles salivales de Streptococcus mutans. Journal of Indian Society of Pedodontics and Preventive Dentistry. Jul - Sept.

9. http://sites.google.com/site/anaerobesystemspricelist/Home/pras-mono-plated-media/Mitis-Salavarius-Agar-with-Tellurite

Correspondencia: Cesar Cayo Rojas

e-mail: cesarcayorojas@gmail.com 